\title{
Saber ser consumidor recreativo: la experiencia de ocio de jóvenes en dos Malls de Lima, uno de alta renta y otro de origen popular
}

How to be a Recreational Consumer: The Leisure Experience of Young People in Two Malls in Lima; One of High Income and Another of Popular Origin

Saber ser um consumidor recreativo: a experiência de lazer de jovens em dois shoppings de Lima, um para alta renda e outro popular

Karina Higa Carbajal ${ }^{*}$

Recibido: 7 de abril del 2019

Aprobado: 15 de abril del 2020

https://doi.org/10.12804/revistas.urosario.edu.co/territorios/a.7845 
Palabras clave

Malls; ocio; consumo recreativo; clases medias; juventudes; espacio público.

Keywords

Malls; leisure; recreational consumption; middles classes; youth; public space.

Palavras-chave

Shopping centers; lazer; consumo recreativo; classes médias; jovens; espaço público.

\section{territarias 44}

\section{RESUMEN}

En este artículo se presenta una reflexión sobre los Malls como espacios privilegiados para el encuentro y ocio en Lima. Mediante una etnografía, se analiza la experiencia de ocio de jóvenes en un Mall ubicado en una zona de alta renta (Jockey Plaza), y otro, en una zona de origen popular en proceso de valorización (Megaplaza). Se evidencia que los usuarios del Jockey Plaza tienen mayor capacidad y seguridad para apropiarse del Mall que los de Megaplaza, puesto que saben ser consumidores recreativos, y con ello, subvertir la alta vigilancia del Mall. Este es un conocimiento práctico que van adquiriendo los usuarios, asociado a cierta posición de clase, relacionado a la ubicación socioespacial donde construyen su cotidianeidad. Si bien se concuerda con la literatura en que el Mall promueve la formación de ciudadanos consumidores, a su vez dicha experiencia es más compleja y ambigua de lo sugerido. Las desigualdades exceden la lógica acceso/exclusión, siendo necesario desarrollar categorías intermedias.

\section{ABSTRACT}

This article presents a reflection about social experience in shopping Malls as privileged spaces for gathering and leisure in Lima. Through an ethnography, we analyze the leisure experience of young consumers of a Mall in a high rent zone (Jockey Plaza) and another in a low rent zone that's going through gentrification (Megaplaza). We show evidence that Jockey Plaza's consumers have more capacity and confidence for spatial appropriation than Megaplaza's for being recreational consumers and with that resource, to subvert the surveillance condition of Malls. This is a practical knowledge that they are acquiring associated with a particular class position, related with the socio spatial location where they build their daily lives. Even if we agree with the narrative that Malls encourage the development of consuming citizens, also this experience is more complex and ambiguous than what it suggests. These inequalities go beyond the logic of access/exclusion, requiring the development of intermediate categories.

\section{RESUMO}

É apresentada uma reflexão sobre os shoppings como espaços privilegiados de reunião e lazer em Lima. Por meio da etnografia, é analisada a experiência de lazer dos jovens em um Shopping localizado em uma área de classe alta (Jockey Plaza), e outro, em uma área de origem popular em processo de valorização (Megaplaza). É evidente que os usuários do Jockey Plaza têm maior capacidade e segurança para se apropriar do Shopping do que os do Megaplaza, pois sabem ser consumidores recreativos e, com isso, subvertem a alta vigilância do Shopping. Trata-se de um conhecimento prático que estão adquirindo associado a determinada posição de classe, que está relacionado à localização socioespacial onde constroem seu cotidiano. Embora concordemos com a literatura que diz que o Shopping promove a formação de cidadãos consumidores, por sua vez, essa experiência é mais complexa e ambígua do que se sugere. As desigualdades ultrapassam a lógica de acesso / exclusão, sendo necessário o desenvolvimento de categorias intermediárias. 


\section{Cuando los Malls llegan a las antiguas periferias de Lima... ¿Igualdad de acceso al ocio y consumo, o nuevas formas de desigualdad urbana?}

En los últimos años - $\mathrm{y}$ con proyección para los siguientes-, se ha dado una expansión acelerada de Malls en Lima, en el marco de un proceso de reestructuración urbana caracterizado por el acceso de flujos de capitales trasnacionales promovidos por las políticas neoliberales desde la década de los noventa (Chion, 2002). Ello ha supuesto cambios en la geolocalización de las dinámicas urbanas, donde los espacios globalizados, inevitablemente asociados al consumo, son muy concurridos para el encuentro y ocio de los limeños (Ludeña, 2009). Según el observatorio ciudadano "Lima Cómo Vamos", el 87,6\% de limeños ha asistido a los centros comerciales durante el 2017, siendo la principal actividad de ocio realizada fuera de la vivienda en todos los niveles socioeconómicos.

La expansión de Malls en Lima se ha dado de manera progresiva partiendo desde sus áreas centrales, donde tienden a concentrarse las zonas de alta renta, hasta sus antiguas periferias, caracterizadas por sus ocupaciones de suelo y vivienda de origen popular e informal que actualmente está en proceso de valorización. El primer Mall abierto tras la reestructuración urbana fue el Jockey Plaza en 1997, ubicado en pleno eje vial de poder de la zona de alta renta (Pereyra, 2006); y el primer Mall inaugurado en un área de expansión fue el Megaplaza en el 2002, ubicado en la actual centralidad más importante de Lima Norte, pero de baja jerarquía a escala metropolitana (Vega Centeno, 2017) (véase figura 1 ).

Las ciencias sociales peruanas han enfatizado en la capacidad de las antiguas periferias, principalmente de Lima Norte, para atraer capital inmobiliario desde el siglo XXI — donde los Malls aparecen como espacios icónicos-, siendo indicador de emergencia de una nueva clase media (Matos Mar, 2004; Joseph, 2005). Acorde a estudios de mercado, la ampliación de la clase media supone una diversidad de estilos de consumo, que establece categorías como el consumidor "moderno", "progresista" o "tradicional", los cuales nada tienen que ver con criterios de desigualdad social (Arellano, 2010). Sin embargo, poco se conoce sobre la experiencia en Malls como espacios urbanos destinados al encuentro y ocio (no solo a la compra), donde el usuario se aborde como actor urbano. Desde esta perspectiva analítica, es importante discutir si la ampliación de la clase media y de la oferta de consumo y ocio en Lima, supone procesos de diferenciación "horizontal" o nuevas formas de desigualdad "intraclase", entre la nueva y la tradicional clase media limeña, siendo los jóvenes quienes han aprendido a ser y estar en la ciudad bajo este contexto desde su socialización primaria. territarias 44

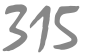




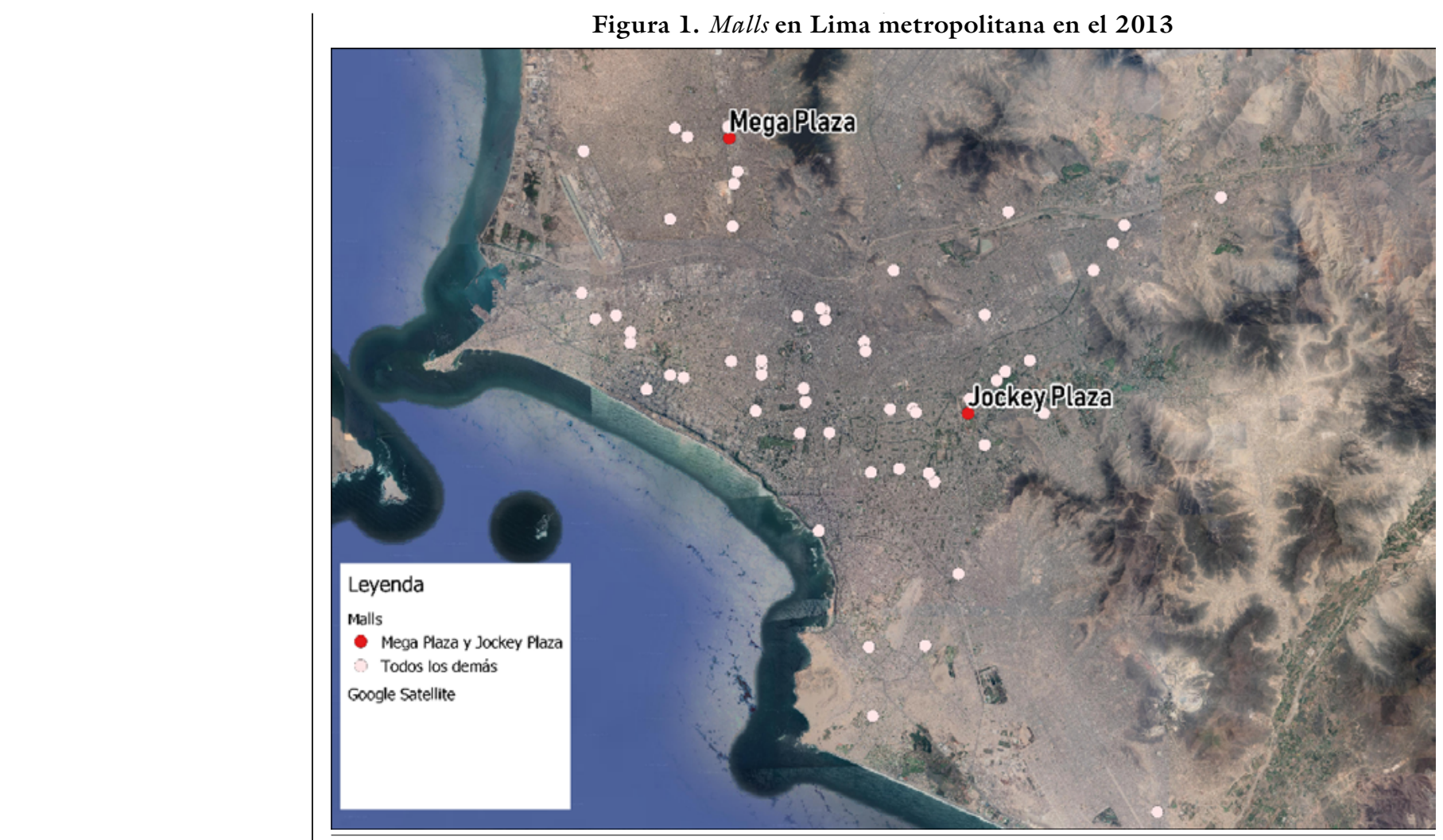

Fuente: elaborado por Kelly Gómez (2020).

Mediante una aproximación etnográfica, esta investigación se pregunta ¿ Cuáles son y cómo se construyen las diferencias en la experiencia de ocio entre jóvenes usuarios del Jockey Plaza y Megaplaza? Durante el trabajo de campo, se descubrió la existencia de jóvenes que asistían cotidianamente a dichos Malls. Esto se debe a que pasan allí sus tiempos libres (intersticiales) de sus actividades educativas, realizadas en el centro urbano donde territarias 44 316 se localiza el respectivo centro comercial.
En ese marco, la dimensión de "clase social" se aborda desde la ubicación socioespacial donde se construye la experiencia educativa, en el sentido amplio del término, y desde donde los jóvenes van adquiriendo determinados recursos culturales. Mediante ello, interesa analizar si la experiencia de ocio entre dichos grupos de clase media supone (o no) desigualdades.

El argumento que se explicará y desde el cual se busca contribuir al debate, es el 
siguiente: los jóvenes usuarios del Jockey Plaza tienen mayor capacidad y seguridad para apropiarse del Mall que los de Megaplaza, puesto que cuentan con recursos culturales para saber ser consumidores recreativos y subvertir la alta vigilancia del Mall. Estos recursos se adquieren o reproducen mediante sus experiencias asociadas al campo educativo, ubicado en el entorno urbano del Jockey Plaza de mayor jerarquía socioespacial (posición de clase).

\section{¡Homogeneidad, heterogeneidad o desigualdad en la experiencia de ocio de jóvenes de clase media en Malls?}

El debate académico sobre la vida social producida en Malls se originó a finales del siglo XX, con la hegemonía que había cobrado el modelo de suburbio norteamericano para producir ciudad en occidente. Urbanistas y científicos sociales enfatizan en el "peligro" que representan los Malls para el ejercicio de la ciudadanía, en tanto son espacios crecientes para el encuentro y ocio que promueven el acceso a quienes son (potenciales) consumidores y excluyen a quienes no (homeless, mendigos, ambulantes). Se advierte sobre la comunidad homogénea y segregada que supone el Mall, donde la identidad se construye desde el consumo (Judd, 1996; Borja, 2003; Staeheli \& Mitchell, 2006); es decir, a partir del reconocimiento y distinción entre individuos por su posesión de mercancías, portadoras de distintos símbolos y niveles de prestigio. Esta clasificación social es promovida por las industrias de consumo (Ritzer, 2003; Crawford, 2004), que ejercen dominación mediante los dispositivos y estrategias de hipervigilancia del Mall (Davis, 1990).

Tras la llegada de los Malls a las metrópolis latinoamericanas - sobre todo desde su entrada a los barrios de origen popular-, investigadores de la región realizaron aproximaciones empíricas a la sociabilidad y ocio en centros comerciales, afirmando que, si bien se excluye a los más pobres, ello no supone la primacía de la homogeneidad social en dichos espacios. Desde los estudios urbanos y de juventudes, se observa que las prácticas socioespaciales en Malls, sobre todo de adolescentes, son más complejas y heterogéneas que el ser consumidores disciplinados. Diversos grupos adolescentes construyen territorios simbólicos en los Malls durante su tiempo de ocio. Esto resulta significativo para crear lazos sociales, fronteras simbólicas, y consecuentemente, la afirmación de sus identidades etarias juveniles acorde a su performance - emos, skaters, pinkys, entre otros-, y su pertenencia a la clase media (Frúgoli \& Pintaudi, 1992; Ariovich et al., 1996; Bermúdez, 2003; Jiménez Domínguez \& Becerra, 2009), por ejemplo, el autodenominarse "ni flaite ni cuico [ni pobre ni rico, con términos despectivos]" en Chile (Pérez, 2010). 
Ello ocurre en pleno proceso dinámico, donde el Mall va aprendiendo y promocionando una oferta de uso y consumo variado, capaz de complacer los deseos y gustos de sus diversos usuarios y, de conciliar la copresencia entre ellos: los gestores del Mall promueven un sentido de pertenencia para todos los grupos de clase media. De hecho, se enfatiza en las negociaciones existentes entre adolescentes y gestores del Mall, quienes se esfuerzan por integrarlos (García Canclini, 1999; Giglia, 2001; Salcedo, 2002; Stillerman \& Salcedo, 2010; Pérez, 2010; Pérez et al., 2012). En tanto, Giglia señala que el Mall ha articulado la tarea de "mantener su hiper seguridad y distinción social, excluyendo a ciertas categorías de personas que no sean potenciales consumidores, pero a su vez (dada su misma lógica de rentabilidad) a diversificar su oferta cultural recreando algo parecido al ámbito público abierto" (2001, pp. 17-18).

Por otro lado, investigadores brasileños se han interesado por aproximarse a quienes están en los márgenes de la oferta de Malls, tras los eventos de represión policial a los rolezinhos entre el 2012 y 2013 en Sao Paulo: jóvenes fans del funk ostentação, estilo musical asociado a lo inmoral ("mal vivir"), quienes habían organizado por redes sociales encuentros en Malls para encontrarse con el fin de entrar a casas funk. Según Caldeira (2014), Viana (2014), Da Silva y Da Silva (2014) y Barbosa-Pereira (2016), la repreterritarios 44 sión de los rolezinhos en Malls evidencia la discriminación frente a la posibilidad de coexistencia como iguales con jóvenes pobres afrodescendientes en espacios comúnmente destinados a las clases medias. La estigmatización hacia sus formas de encuentro y ocio, consideradas como potencial peligro, refuerza la segregación urbana, lo cual podría traer consigo la violencia urbana por parte de los "oprimidos”. Ello prueba los límites y riesgos de destinar una función pública a los espacios privatizados para la construcción de una ciudad justa, tolerante y diversa.

La literatura sostiene que los mecanismos de desigualdad social en los Malls yacen en las oportunidades de acceso. En ese sentido, las diferentes formas de ocupar el Mall por quienes pueden acceder, nada tiene que ver con la (re)producción de desigualdades urbanas en Latinoamérica; al contrario, se enfatiza en la posibilidad de "negociarlas" dentro de los Malls (Stillerman \& Salcedo, 2010), siguiendo una lógica de mercado que todo lo puede asimilar (Giglia, 2001).

En cambio, el presente estudio sostiene que la lógica de acceso/exclusión, si bien es el mecanismo más agudo de desigualdad social, no es el único existente en el marco de la ampliación de la clase media latinoamericana, y en particular, en el caso de Lima. Se busca demostrar que la expansión del acceso a una oferta de ocio y consumo "contextualizada", pensada para integrar la diversidad de gustos de sus usuarios (dimensión que enfatizan los estudios previos), podría 
mitigar mas no anular la desigualdad en los recursos (materiales como simbólicos) con los que los propios usuarios cuentan para apropiarse de un espacio como el Mall, inevitablemente asociado al consumo. La coexistencia entre ambas situaciones evidencia la complejidad y ambigüedad del Mall como espacio social $\mathrm{y}$, de las micro situaciones de desigualdad existentes en los grupos de clase media en sus experiencias de ocio.

\section{Habitar el Mall es habitar su entorno: propuesta metodológica}

La investigación es una aproximación etnográfica a las experiencias de ocio de jóvenes que acuden cotidianamente al Jockey Plaza y Megaplaza, realizada entre el 2015 y el 2017. Se escogió a dichos Malls, ya que representan hitos para Lima en el proceso de reestructuración urbana de fines del siglo Xx, y en la vida cotidiana de sus habitantes.

Jockey Plaza es el Mall más grande de Lima $\left(174821 \mathrm{~m}^{2}\right)$ siendo el de mayor facturación anual (Asociación de centros comerciales y entretenimiento del Perú, ACCEP, 2015) y el más recordado por los limeños (Arellano Marketing, 2014). Fue el primer Mall inaugurado tras la reestructuración urbana en 1997, ubicado en la zona de alta renta de Lima en el distrito de Surco (véase figura 2). Se localiza en pleno eje vial de poder a nivel metropolitano (Pereyra, 2006), próximo a un centro financiero emergente (Vega
Centeno, 2017) y a una concentración educativa de centros privados de idiomas, básicos regulares y universitarios predesregularización, conocidos por sus elevados costos (véase tabla 1 ), accesos exclusivos y sus altos estándares de calidad y prestigio (Huber \& Lamas, 2017) (véase figura 3 ).

Megaplaza es el segundo Mall más grande de Lima $\left(138311 \mathrm{~m}^{2}\right)$ siendo el tercero con mayor facturación anual (ACCEP, 2015) y el más visitado por los limeños (Arellano Marketing, 2014). Fue el primer Mall inaugurado en un área de expansión de origen popular e informal en proceso de valorización en el 2002, en el distrito de Independencia (véase figura 2). Megaplaza forma parte de la centralidad más importante de Lima Norte, aunque de baja jerarquía a nivel metropolitano (Vega Centeno, 2017). Allí se encuentra una concentración laboral del sector automotriz, maderero, de comercio formal e informal, así como una concentración educativa de tipo preuniversitaria, de idiomas, técnica y universitaria posdesregularización. Esta última, conocida por sus bajos costos (véase tabla 1), ingresos masivos y estándares mínimos de calidad y prestigio (Huber \& Lamas, 2017) (véase figura 4).

Ya situados en ambos Malls, se seleccionó como muestra a usuarios que acuden regularmente a dichos centros comerciales para el encuentro y ocio. Son jóvenes que construyen parte importante de su vida cotidiana en el centro urbano 
Figura 2. Plano estratificado por ingreso per cápita del hogar de Lima metropolitana en el 2013

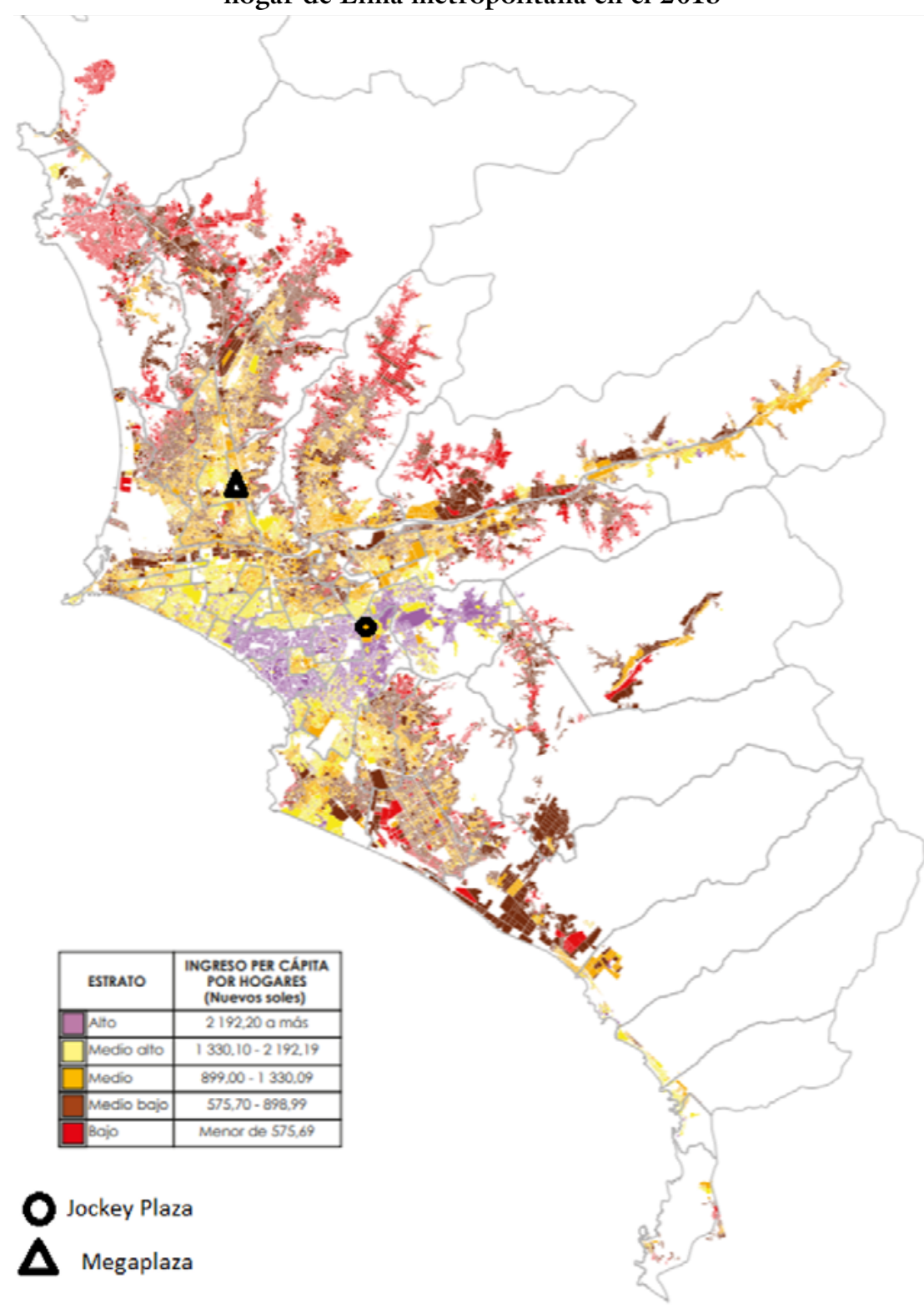

territarias 44

Nota: La ubicación de Malls es elaboración propia.

Fuente: Instituto Nacional de Estadística e Informática (INEI, 2013). 
Figura 3. Mapa del entorno urbano del Jockey Plaza

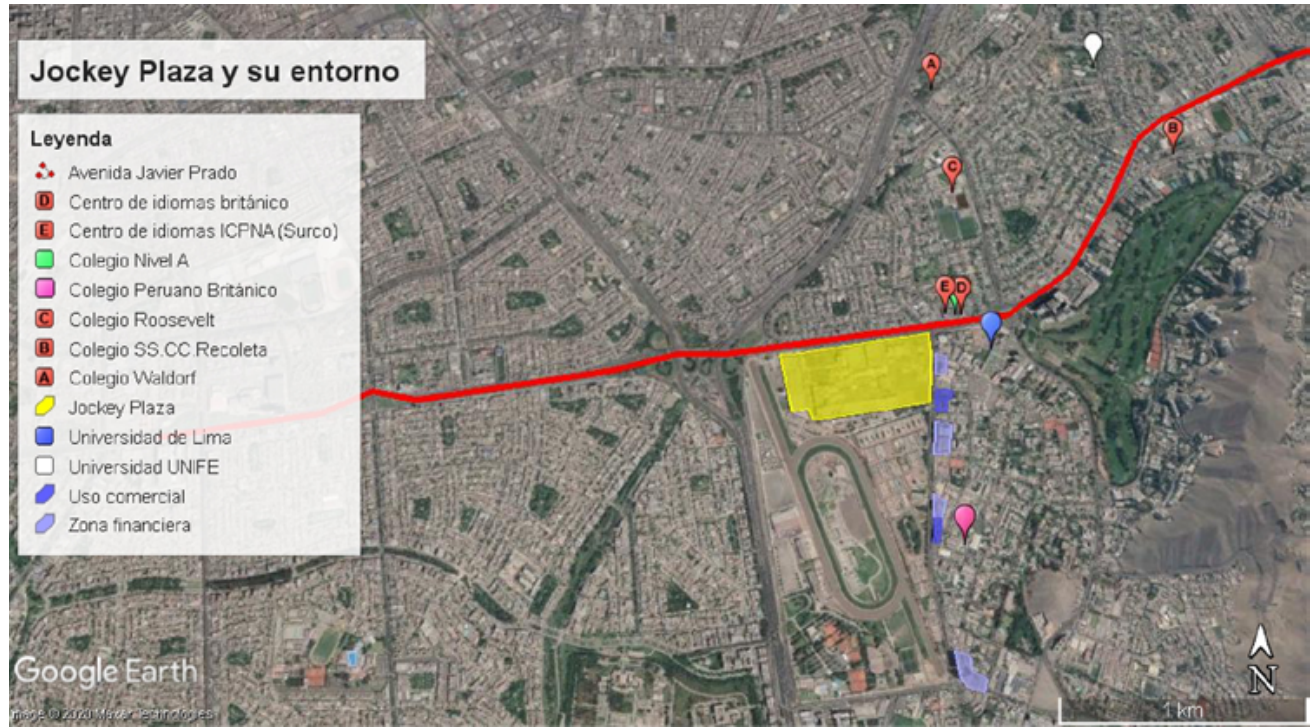

Fuente: elaboración propia (2020).

Figura 4. Mapa del entorno urbano de Megaplaza

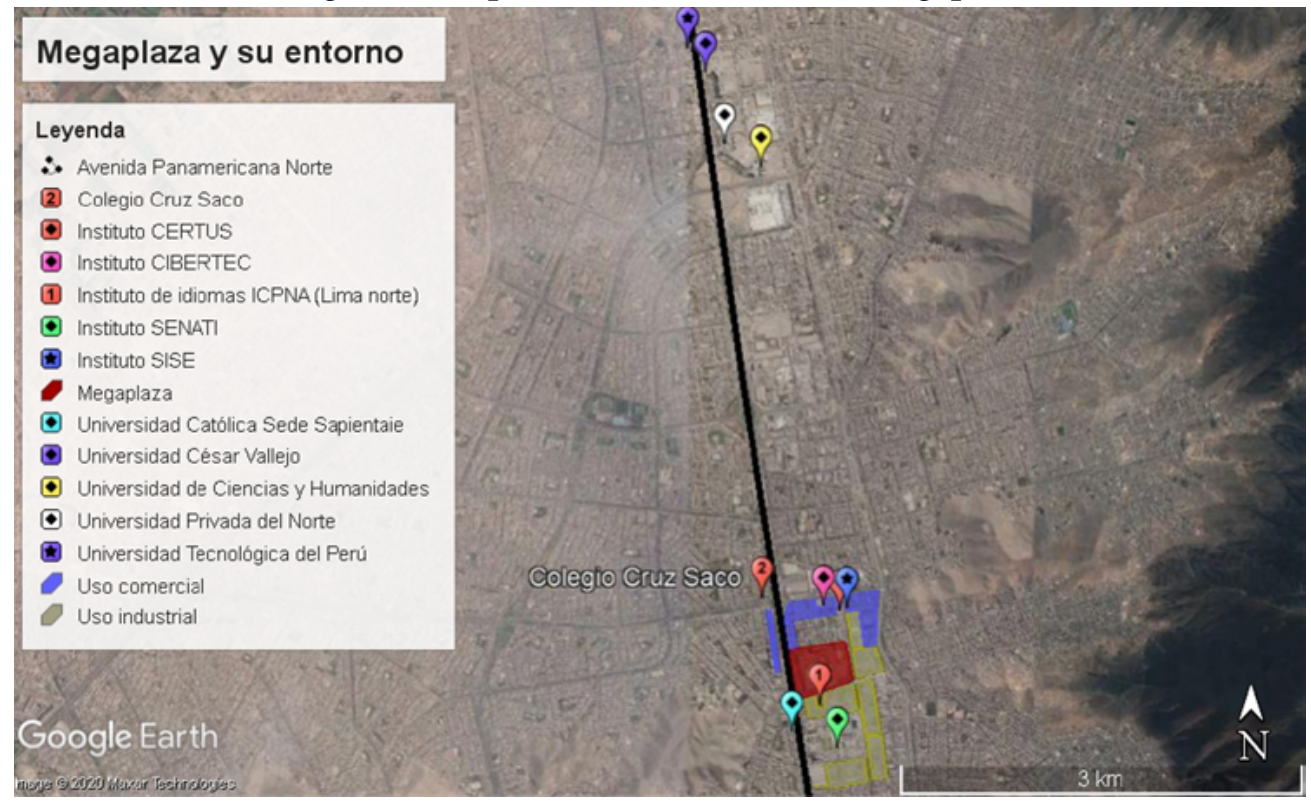

Fuente: elaboración propia (2020). 
Tabla 1. Pensiones mensuales de centros educativos superiores en el 2015

\begin{tabular}{|l|l|c|}
\hline \multicolumn{1}{|c|}{ Centros educativos superiores } & \multicolumn{1}{c|}{ Ubicación } & Costos \\
\hline Universidad de Lima & Próximo a Jockey Plaza & $1432-2869$ \\
\hline $\begin{array}{l}\text { Universidad Femenina del Sagrado Corazón } \\
\text { (UNIFE) }\end{array}$ & Próximo a Jockey Plaza & $1080-1870$ \\
\hline Universidad San Martín de Porres & Sede relativamente próxima a Jockey Plaza & $906-4351$ \\
\hline Colegio Peruano Británico & Próximo a Jockey Plaza & 2464 \\
\hline Colegio Nivel A & Sede próxima a Jockey Plaza & 1150 \\
\hline Colegio Roosevelt & Próximo a Jockey Plaza & 4468 \\
\hline Colegio SS.CC. Recoleta & Próximo a Jockey Plaza & 1400 \\
\hline Instituto superior SENATI & Sede central próxima a Megaplaza & 548 \\
\hline Instituto superior SISE & Sede próxima a Megaplaza & $480-650$ \\
\hline Instituto superior CIBERTEC & Sede próxima a Megaplaza & 745 \\
\hline Universidad Tecnológica del Perú & Sede próxima a Megaplaza & $760-790$ \\
\hline Universidad Católica Sede Sapientaie & Próximo a Megaplaza & $425-654$ \\
\hline Universidad César Vallejo & Sede central próxima a Megaplaza & $550-650$ \\
\hline Universidad Privada del Norte & Sede central próxima a Megaplaza & $570-634$ \\
\hline
\end{tabular}

Nota: costos aproximados en soles. Fuente: elaboración propia a partir de grupo Educación al

Futuro y la plataforma Ponte en Carrera del Ministerio de Educación del Perú (2020).

donde dichos Malls se localizan, dado que allí se ubican sus instituciones educativas. Estos grupos de jóvenes acuden a los Malls durante sus tiempos libres intersticiales antes, entre o después de sus clases.

Mediante la observación participante, se buscó indagar en sus prácticas cotidianas en el Mall, así como sus valoraciones sobre ellas y sus interacciones con trabajadores, con el fin de analizar si ello supone situaciones de ventaja o desventaja en el uso de dicho espacio. Además, mediante 10 entrevistas en cada grupo de jóvenes (usuarios de Megaplaza y Jockey Plaza), se buscó identificar recursos (específicamente redes sociales y sus circuitos de ocio), y sus valoraciones sobre ello con base en sus trayectorias, cuyo trabajo analítico supuso la construcción de tipos ideales. El objetivo es comprender por qué se dan las diferencias en sus modos de ocupar el Mall, buscando conocer si está asociado a 
cierta posición de clase, o contrario a ello, se debe exclusivamente a una disposición individual o a la capacidad de control y vigilancia del Mall.

Desde esa perspectiva, se aborda la dimensión de "clase" con base en la ubicación socioespacial donde se habita cotidianamente en la ciudad y desde donde se van adquiriendo determinados recursos. En este caso, se identifican las implicancias para los jóvenes de estudiar próximos o en pleno eje vial de poder de la zona de alta renta de Lima, el cual tiene mayor jerarquía metropolitana (Pereyra, 2006), o en la centralidad de Lima Norte, la cual tiene menor jerarquía metropolitana (Vega Centeno, 2017).

En síntesis, ser parte de la experiencia de los jóvenes durante su tiempo libre intersticial en el Mall, el cual forma parte de sus circuitos cotidianos realizados en centros urbanos de distintas jerarquías socioespaciales, fue la apuesta metodológica de la investigación.

\section{Micro desigualdades en la experiencia de ocio entre jóvenes usuarios del Jockey Plaza y Megaplaza}

\section{Jockey Plaza}

El circuito del consumo recreativo. Los jóvenes que acuden al Jockey Plaza durante su tiempo libre intersticial, suelen dedicarse a merodear en los pasillos del Mall de manera juguetona, participando de las activaciones de marcas, vitrineando y entrando de tienda en tienda que les resulte atractiva para fisgonear, rebuscar y jugar con los productos exhibidos. Cuando permanecen en algún sitio en los pasillos - que es cuando los pude conocer-, suele ser a modo de descanso como consecuencia su actividad movible:

Entramos a Apple Store y nos tomamos fotos con los iPads en muestra con los efectitos de la cámara, solo por chongo [juego]. También en las tiendas de videojuegos, jugamos cuando están en muestra, sobre todo cuando está el guitar [...]. Probarnos ropa también. Vamos a Ripley [retail] y la vestimos chistoso a una amiga, con una falda laaaarga (Joven 18 años, comunicación personal, 2016).

[...] Samsung [marca] estaba hace poco mostrándote los celulares mediante unos videojuegos [realidad virtual], entonces, de curiosos o por pasar el rato no más, hicimos esas cosas (Joven 19 años, comunicación personal, 2016).

Nos buscamos la ropa más fea de la sección de señoras que es carísima, y nos probamos y tomamos fotos en el espejo para cagarnos de risa [carcajearse] (Joven 17 años, comunicación personal, 2016).

La experiencia de los jóvenes en el Jockey Plaza se construye en torno al consumo recreativo. La performance y circuito alrededor de la compra es su tersitarias 44 
modo de divertirse, sin que ello implique necesariamente tener interés en adquirir la mercancía. Incluso, los jóvenes buscan probar productos que no comprarían como la ropa que les parece "más chistosa", “más fea”, o aparatos electrónicos con los que ya cuentan personalmente (iPhone, videojuegos). Esto se debe a que el interés está en la posibilidad de jugar colectivamente mientras "hacen hora" (en sus palabras) hasta que empiecen, deban retornar a sus clases o a sus casas. De este modo, el circuito del consumo es interpretado como un juego y no como un paso previo a la decisión de compra.

Soy consumidor, pero no compro (conciencia práctica). Los trabajadores de las tiendas del Mall expresan su incomodidad frente al consumo recreativo de los jóvenes, a quienes ya suelen reconocer en algunos casos: "son las caras de los mismos chibolos [jóvenes en modo despectivo] que vienen a desordenarme toda la ropa", comentan trabajadores de retails. Sin embargo, ellos no se sienten en la autoridad de prohibirles, o si quiera limitarles sus acciones, ya que los jóvenes juegan dentro de las reglas aceptadas por el Mall: "estamos actuando como clientes", como indica un usuario.

Hay momentos donde vienen chibolos, grupos de 7-8, entre 15-18 años, a ver juegos, discos, pero de chongo, y uno tiene que atenderlo, pero al final no te van a comprar nada, entonces prácticamente estás perdiendo tu tiempo. Pero igual sabes que tienes que atenderlo [...] son casos frecuentes, yo diría que el $50 \%$ de veces ocurre al día (Trabajador de Phantom music \& videogames, comunicación personal, 2016).

Es estresante, están por ahí jugando [...] $\mathrm{Mi}$ [jefe] superior me dice que arregle [la ropa] no más, y a los chicos tampoco se les puede decir nada (Trabajadora de retail Ripley, comunicación personal, 2015).

Cuando los trabajadores y jóvenes comienzan a reconocerse entre ellos, sus interacciones tienden a basarse en un intercambio de miradas un poco tensas, pero que los jóvenes pasan por desapercibidas. Ellos cuentan con la seguridad de que nadie puede prohibirles sus prácticas cotidianas en Jockey Plaza.

Venía a Crisol [librería] a leer libros [...] me quedaba dos, tres horas. El wachiman [personal de seguridad] me miraba con cara de ¡oye, nunca compras nada! Podía verlo en su mirada, pero meh [actitud indiferente], nunca me botaron [...] En el segundo ciclo, cuando no tenía amigos en la $u$ [universidad] (risas), iba casi todos los días (Joven 21 años, comunicación personal, 2015).

Los de seguridad de Apple Store sí te miran, pero, ¿están haciendo su trabajo, no? Supongo que habrá robos o gente sospechosa, pero nosotros solo venimos a huevear [pasar rato]. El vigilante de seguro 
también se ríe de lo que hacemos (Joven 22 años, comunicación personal, 2016).

Soy consumidor, pero no compro (conciencia discursiva). La capacidad con la que cuentan los jóvenes para apropiarse del espacio no solo opera a nivel práctico, sino también a nivel discursivo. Cuando se les pregunta directamente sobre la posibilidad de ser reprendidos por sus prácticas cotidianas en el Mall, los jóvenes protegen $\mathrm{y}$ defienden con rigor y seguridad su derecho al uso de dicho espacio en condición de consumidores:

B: Una trabajadora me decía que hay chicos que se prueban ropa de juego y la desordenan. Eso le incomoda.

A: No se puede molestar por hacer su trabajo. Aunque no compren, se están probando ropa, es parte de toda la experiencia que ofrece un centro comercial, ¿no? (Joven 18 años, comunicación personal, 2016).

B: ¿El personal de seguridad alguna vez les ha reprendido?

A: No, menos mal, porque si no yo también habría covntestado, porque no se está haciendo nada malo. En realidad, estamos actuando como clientes (Joven 17 años, comunicación personal, 2016).

Es interesante dar a conocer la forma como los jóvenes, desde sus propias prácticas y discursos, interpretan el significado de lo que es "ser consumidor", reconociéndose como tal. Este se relaciona con la performance y experiencia alrededor de la compra, pero no necesariamente con el intercambio mercantil. De ese modo, justifican su práctica en el Mall como legítima.

Los jóvenes suelen estar a la expectativa de renovaciones y activaciones constantes para evitar caer en la repetición excesiva de circuitos de consumo recreativo. Dada la regularidad de su práctica, los cambios que el Mall realiza no suplen su búsqueda de estímulos inmediatos. Así pues, son frecuentes los testimonios sobre el aburrimiento o el deseo de una mayor oferta de consumo recreativo:

Algo como el Jockey, “o sea” [tono y expresión despectiva] [...] Me da igual, es lo que hay... a nada. Ya me lo conozco de pies a cabeza, lo tengo casi de memoria fotográfica (Joven 21 años, comunicación personal, 2015).

No hay qué hacer [en Jockey Plaza] porque es lo mismo, como venimos aquí todos los días, ya nos aburrimos [...] Para chibolos hay todo, pero para más grandes... (Joven 18 años, comunicación personal, 2016).

\section{Megaplaza}

La mega plaza local. Los jóvenes que acuden a Megaplaza durante su tiempo libre intersticial suelen permanecer en 
algún sitio fijo en los pasillos, plazuelas o balcones, a los que llaman sus points. Ellos han encontrado allí el acondicionamiento ideal para las experiencias que buscan tener en Megaplaza, la cuales tienden a estar al margen del consumo:

[4:15 p. m.] Hay muchas parejas jóvenes [...] Ninguna mira hacia las tiendas ni parece interesarse por ellas [...] Una pareja joven estaba sentada al rincón del balcón, detrás de un florero que los tapaba casi completamente. Tal rinconcito no estaba diseñado para que la gente permanezca allí, pero creo que por esa razón la pareja estaba allí. Les daba cierta sensación de intimidad, de estar escondidos (Nota de campo, 2015, 30 de octubre).

[9:30 a. m.] Ningún presente estaba esperando que abriera alguna tienda para comprar o pagar servicios (excepto quienes hacían cola en Claro [telefonía]). Realizaban sus actividades de descanso matutinos: leer su periódico o biblia, escuchar música, conversar, tomar su desayuno comprado en los puestos ambulantes de afuera del Mall, hacer hora hasta que comiencen las clases. Algunos hasta cabeceaban [dormir]. También había parejas de enamorados con sus uniformes escolares, quienes habían preferido no ir a clases para pasar tiempo juntos (Nota de campo, 2016, 10 de junio).

Los jóvenes realizan una multiplicidad territarias 44 de actividades alternativas al consumo en Megaplaza, a modo de una plaza pública.
Si encontramos jóvenes merodeando en los pasillos, suele ser porque andan buscando algún sitio donde les resulte cómodo permanecer, rara vez se interesan por entrar a tiendas, participar de las activaciones de marca o de los espectáculos masivos que comúnmente realiza Megaplaza.

Los limites de no ser consumidor. La ocupación fija de los jóvenes ha llevado a que sean fácilmente reconocidos entre ellos y por mí, pero también por algunos trabajadores del Mall. Esto es percibido como una situación de tensión, pues el rol de los trabajadores les hace tener presente que están en un espacio con fines de lucro, donde las actividades al margen del consumo tienen un límite:

A: cuando estaba la pantalla en el food court, íbamos a ver los partidos [de fútbol]. Guardábamos sitio porque todo se llena [...] Un amigo que había acabado [sus clases] antes, nos estaba guardando el sitio desde dos horas antes, pero al final no pudimos ver sentados porque el vigilante nos dijo que las mesas eran para los que estaban consumiendo [...]

B: ¿Siempre los botan cuando no consumen?

A: no, es que ese día estaba lleno, había gente. Pero otros días sí te dejan estar ahí (Joven 20 años, comunicación personal, 2016). 
Esto deja ver la autoridad que los trabajadores tienen para, en el momento que consideren necesario, pedir que se retiren a quienes no están consumiendo. La función "pública” del Mall, como espacio de libertad para el encuentro y ocio, es posible en tanto no obstaculice su propósito central, que es promover y facilitar los usos para el consumo. El paso y la comodidad de los consumidores reales siempre serán preferidos en contraste al de "chibolos que siempre están por ahí tonteando [referencia despectiva por tener tiempo libre]", como indica un agente de seguridad.

Se evidencia que los consumidores cuentan con mayores derechos al uso del espacio que quienes han organizado una estrategia colaborativa para separar dicho sitio por horas. He ahí la especial relevancia para los jóvenes de encontrar múltiples points, y evitar espacios como el food court, tratando continuamente de evitar encuentros con trabajadores reconocibles. Esto, con el fin de poder desplegar sus actividades cotidianas sin obstruir el paso a consumidores. Además, ellos aprenden a convivir con sentirse "mal vistos" por los trabajadores, como veremos a continuación.

Soy libre pero sospechoso porque no consumo. Cuando se explora en los discursos de los jóvenes, se evidencia que, no solo los trabajadores deslegitiman su uso cotidiano del Mall, sino que son ellos mismos quienes dudan de su derecho al uso del espacio en su condición de usuarios recurrentes no consumidores. Algunos incluso creen que son "objetos de sospecha" para los trabajadores, al ser probablemente confundidos con actores no permitidos dentro de los Malls o hasta delictivos:

Los de acá [una tienda] se han puesto ahí [en la puerta] a ver qué estamos haciendo, nunca se ponen así. También los de seguridad, siempre me miran, supongo que se preguntarán: ¿̨estará vendiendo algo? Pero nunca me han dicho nada (Joven 19 años, comunicación personal, 2015) [cree que lo confunden con vendedor ambulante].

¿Qué dirán [los de seguridad], no? Que este siempre viene, se sienta ahí, que soy un sospechoso que viene a analizar el funcionamiento del lugar ¿entiendes? Me da vergüenza que me estén mirando, y yo soy pobre (risas), no me alcanza ni para una hamburguesa, porque si viniera todos los dias para almorzar sería diferente (Joven 20 años, comunicación personal, 2016) [cree que lo confunden como cómplice de un robo].

Los usuarios de Megaplaza tienden a sentirse directamente aludidos por la vigilancia del Mall, a diferencia de la impersonalidad con la que se lo toman los usuarios del Jockey Plaza. Esta sensación se intensifica cuando dicha vigilancia deja de ser una condición abstracta del lugar, y pasan a ser personas con rostros reconocibles. Aunque es importante rescatar territarias 44 
que no se conoce ningún caso de autoexclusión. Esto se debe a que los mismos jóvenes también valoran la posibilidad de hallar un lugar "seguro", "tranquilo" e “íntimo" en los pasillos del Mall, a diferencia de los usuarios del Jockey donde destacan valoraciones en torno al aburrimiento e insatisfacción sobre dicho lugar. En Megaplaza, los jóvenes valoran el poder sentir la libertad de disfrutar de la compañía de su pareja, de una charla entre amigos o de su individualidad, que en otros espacios que frecuentan cotidianamente no tienen, como sus hogares, barrios, escuelas, asociados al control social u otros espacios públicos aledaños, como parques y plazas.

Este es mi point cuando vengo solo, porque aquí es más tranquilo. Abajo hay más gente, es incómodo, viene un niño a ver qué estás haciendo [...] también salgo por mi casa donde hay un centro comercial, pero no tan grande como Mega. Por abi paro con mis amigos del barrio, o me los cruzo (Joven 19 años, comunicación personal, 2015).

Yo siempre me siento aquí a esta hora, es fácil ubicarme [...] desde aquí tengo un buen ángulo para dibujar [...] [Vengo acá] también un poco para perder el tiempo, porque en mi casa es...complicado (Joven 21 años, comunicación personal, 2016).

Ana, Kata y Francisa (18, 18 y 19 años) dicen que se sienten libres en Megaplaza porque pueden conversar de cualquier tema, además de sentirse seguras paseando allí, a diferencia de los parques/plazas donde se sienten vulnerables y sus mamás se preocupan más (Nota de campo, 2015, 2 de noviembre).

De este modo, los jóvenes transitan en mecanismos de apropiación y tensión en el uso del espacio del Mall: entre desplegar sus actividades de encuentro y ocio, y, sentirse vigilados por no estar consumiendo.

\section{El entorno de Jockey Plaza y Megaplaza: micro desigualdades en la experiencia de ocio y de amistad que trae la vida estudiantil}

Las diferentes formas de ocupar el Mall entre los jóvenes usuarios del Jockey Plaza y Megaplaza, y las posiciones de ventaja y desventaja que suponen, se relacionan con los distintos recursos culturales con los que cuentan. Estos recursos se adquieren o reproducen mediante sus experiencias asociadas al campo educativo, ubicado en el entorno urbano de los respectivos Malls.

Ambos grupos de jóvenes tienen a los estudios como actividad principal en tanto es el eje que organiza su rutina cotidiana, además de estar subvencionada por sus padres. Por lo que las diferencias están en la red de amistades, los circuitos de ocio que la experiencia educativa en cada zona de Lima trae consigo y que los jóvenes valoran de acuerdo con sus 
trayectorias de vida. Para analizar ello, se han construido tipos ideales, en los cuales dos de ellos pertenecen a cada grupo de jóvenes (véase tabla 2).

\section{Usuarios de Jockey Plaza}

\section{Tipo 1. Continuidad \\ del consumo recreativo}

Son jóvenes que han construido sus vidas cotidianas, tanto habitar como residir, casi exclusivamente en las zonas de alta renta de Lima. Sus viviendas están localizadas allí, además de estudiar en la escuela, realizar múltiples actividades extracurriculares y construir circuitos de ocio en dicha zona de la ciudad.

Sus experiencias educativas, donde el Mall es parte del tiempo y espacio intersticial entre clases, representan para ellos (i) una continuidad de los circuitos de ocio que han mantenido desde su infancia temprana, y (ii) la ampliación de redes de amigos con formas similares de divertirse.

Desde temprana edad, los circuitos de ocio estaban asociados a recurrir a distintos restaurantes globalizados, Malls, parques temáticos, arcades, cabinas de videojuegos, bowling, etcétera. Recuerdan mucho las fiestas infantiles en dichos establecimientos en compañía de los padres. Llegado a la adolescencia, se enfatiza en cómo se adquirió mayores libertades al salir sin los padres, dándoles el espacio para desarrollar capacidades de ser más "vivos" en el juego del consumo recreativo: (risas) ahí fue cuando empecé a robar en los supermercados. Me volví experta robando piqueos, queso y cabanossi, que lo comíamos entre todos, porque nuestros padres nos daban 20 soles por salida y no nos alcanzaba (Joven 18 años, comunicación personal, 2016).

\section{Tipo 2. Aprendizaje del consumo recreativo}

Son jóvenes que no residen pero que sí habitan las zonas de alta renta, al llevar clases extracurriculares allí o por estudiar en la escuela (normalmente superior) ubicada en dicha zona. Ello los ha llevado a establecer redes de amigos y localizar sus circuitos de ocio también en esta área de la ciudad.

Sus experiencias educativas han significado para ellos un aprendizaje nuevo en las formas de divertirse, siendo la experiencia del consumo recreativo. Este grupo enfatiza en las nuevas amistades que han ganado con el acceso a la escuela en dicha zona, al contrastarlo con sus amistades "de tiempo", asociadas a su lugar de residencia o la escuela previa (normalmente la básica regular):

Mis amigas de la universidad viven por La Molina [...] [por ahí] es tranquilo, no hay mucha bulla, se ve bonita la zona, ordenada. Pero es que tú vas, y solo paras adentro, no sales, y cuando te cruzas con alguien, no lo saludas; en cambio, cuando yo salgo por mi casa, "vecino, buenos días", territarias 44 
o te encuentras a tus amigos, y empiezas a hablar, hablar y hablar. Mis amigas de la universidad [...] dicen bastante para ir a Do it, donde venden accesorios, como pulseras, aretes [...] A mí no me gustan esos, casi no uso, ¿̀ves? [...] De ahí, a ver las siguientes tiendas de ropa [...] Normal acompañarlas (Joven 18 años, comunicación personal, 2016).

Cabe precisar que, acorde a nuestra observación participante, este grupo sigue mas no lidera los circuitos de consumo recreativo en el Mall. No se observa la misma seguridad ni destreza de sus amistades que lo practican desde la socialización temprana.

\section{Usuarios de Megaplaza}

\section{Tipo 3. Continuidad de sociabilidad (al margen del consumo) en espacios comerciales}

Son jóvenes que han construido parte importante de sus vidas cotidianas, tanto habitar como residir en las antiguas zonas de expansión de Lima (de renta media). Sus viviendas están localizadas allí, además de estudiar en la escuela y construir sus circuitos de ocio en dicha zona de la ciudad.

Las experiencias educativas representan para ellos, en primera instancia, la ampliación de redes de amigos con formas territarios 44 similares de divertirse, las cuales rara vez están asociadas exclusivamente al consumo. Ello implicaría la continuidad de circuitos de ocio, donde hay una interconexión entre el uso de locales comerciales (como cabinas de internet y videojuegos, arcades, restaurantes globalizados, etc.) y la calle adyacente, enfatizando en sus ocupaciones fijas (points) desde sus discursos. Además, desde temprana edad, se suele realizar tales circuitos sin compañía de adultos, aunque en zonas próximas a la vivienda o escuela.

\begin{abstract}
Por mi casa también hay tiendas, cine. Hay un McDonald's, discotecas. Por ejemplo, voy al McDonald's y están abi haciendo tiempo o haciendo hora caminando por las calles de ahí, como la zona es bien luminosa, para distraerse, por ahí los ves siempre [...] todos van ahí por lo que te digo. Es el punto de encuentro del barrio (Joven 19 años, comunicación personal, 2015).
\end{abstract}

Cabe explicitar que no se identificaron experiencias asociadas al consumo recreativo como práctica sistemática de ocio. En segunda instancia, la experiencia educativa también representa el descubrimiento colectivo (propio de esta etapa de su vida) y valoración de la libertad que brinda el anonimato, al usar un espacio masivo como el Mall para el encuentro y descanso. Incluso, pese a las tensiones que se perciben en dicho espacio, lo contrastan con la vigilancia barrial y familiar que observan como mucho más limitante. 
Podemos ver los perfiles [de redes sociales] de la gente (risas) [...] aquí [en el Mall] se puede $[. .$.$] en mi casa es incómodo porque$ la computadora está en el comedor (Joven 18 años, comunicación personal, 2016).

Prefiero estar solo aquí [en el Mall] [...] porque si paro por allá [barrio], después, le dicen a mi mamá que estoy vagando (Joven 19 años, comunicación personal, 2016).

El insertar la ocupación cotidiana del Mall, en tanto espacio de libertad y anonimato, como parte de sus circuitos de ocio es un recurso nuevo aprendido.

\section{Tipo 4. Aprendizaje de sociabilidad (al margen del consumo) en espacios comerciales}

Son jóvenes que residen en las nuevas zonas de expansión de Lima (renta baja), muchas de ellas de ocupación informal. Pero que, a su vez, construyen parte importante de sus vidas cotidianas en las antiguas zonas de expansión de Lima (renta media). Suelen llevar actividades extracurriculares allí o estudiar (normalmente la etapa superior técnico o universitario) ubicada en dicha zona. Ello los ha llevado a establecer redes de amigos y localizar sus circuitos de ocio también en esta área de la ciudad.

Sus experiencias educativas han significado para ellos (i) también el descubrimiento de la libertad que brinda el anonimato en espacios masivos (como el
Mall) frente a su barrio o familia, pero, además, (ii) un aprendizaje o intensificación en las formas de divertirse en espacios comerciales locales y globalizados. Este grupo enfatiza en las nuevas amistades que han ganado con el acceso a la educación superior, al contrastarlo con sus amistades "de tiempo", asociadas a su lugar de residencia o a la escuela previa (normalmente la básica regular):

Con mis amigos del barrio, nos juntábamos en la esquina, todas las tardes, desde pequeños, jugábamos trompo, yo-yo, con la patineta, como la calle es de la ladera $[\ldots]$ eso de ir a cabinas de internet era una a las quinientas. A veces nos prestaban celulares y nos juntábamos a jugar $[\ldots]$ Con los amigos del instituto se ha vuelto cosa de todas las semanas enviciarte con eso (risas) (Joven 20 años, comunicación personal, 2016).

Existe una alta valoración frente a la posibilidad de usar el Mall de manera regular, no solo por ser el lugar donde descubrieron la libertad del anonimato, sino por identificarlo como "moderno", “ordenado" y "bien arreglado". Esto, porque lo contrastan con sus barrios y alrededores, establecidos en zonas de ocupación informal y autoconstruidas.

A partir de lo explicado, se sostiene que la capacidad y seguridad con la que se cuenta para apropiarse del Mall parte de una posición de clase, siendo el aprendizaje del consumo recreativo lo que otorga territarias 44 
ventaja. Esto, porque permite subvertir la alta vigilancia del Mall.

Queda pendiente explicar las diferencias en la seguridad para defender discursivamente su derecho al uso del espacio en específico. Como dice una entrevistada (del tipo 2) refiriéndose a su nueva amiga de la universidad: "ella no se queda callada". ¿ Cómo se adquiere tal habilidad? Nuestra hipótesis es que, además del propio consumo recreativo, se debe a ciertas pautas de crianza por algunos grupos de clase que priorizan el empoderamiento, liderazgo y habilidades de negociación, en contraste con otros que promueven la disciplina, respeto a la autoridad y obediencia. Ello excede los alcances de la presente investigación.

Tabla 2. Tipos ideales

\begin{tabular}{|c|c|c|c|c|c|}
\hline \multirow{2}{*}{\multicolumn{2}{|c|}{$\begin{array}{l}\text { Dimensiones de análisis } \\
\text { y comparación }\end{array}$}} & \multicolumn{2}{|c|}{ Usuarios de Jockey Plaza } & \multicolumn{2}{|c|}{ Usuarios de Megaplaza } \\
\hline & & Tipo 1 & Tipo 2 & Tipo 3 & Tipo 4 \\
\hline \multicolumn{2}{|c|}{$\begin{array}{l}\text { Ubicación socioespacial } \\
\text { donde ocurre su vida cotidia- } \\
\text { na, centrada en los estudios }\end{array}$} & $\begin{array}{l}\text { Residen y ha- } \\
\text { bitan en zonas } \\
\text { de alta renta. }\end{array}$ & $\begin{array}{l}\text { Habitan pero no } \\
\text { residen en zonas } \\
\text { de alta renta } \\
\text { (sino de renta } \\
\text { media o baja). }\end{array}$ & $\begin{array}{l}\text { Residen y habi- } \\
\text { tan en zonas de } \\
\text { renta media. }\end{array}$ & $\begin{array}{l}\text { Habitan pero } \\
\text { no residen en } \\
\text { zonas de renta } \\
\text { media (sino de } \\
\text { renta baja). }\end{array}$ \\
\hline \multirow{3}{*}{$\begin{array}{l}\text { Recursos } \\
\text { culturales }\end{array}$} & $\begin{array}{l}\text { Valoración } \\
\text { de la amistad } \\
\text { en la escuela }\end{array}$ & $\begin{array}{l}\text { Ampliación de } \\
\text { redes de ami- } \\
\text { gos con formas } \\
\text { similares de } \\
\text { divertirse. }\end{array}$ & $\begin{array}{l}\text { Nuevas redes } \\
\text { de amigos, con } \\
\text { formas distintas } \\
\text { de divertirse. }\end{array}$ & $\begin{array}{l}\text { Ampliación de } \\
\text { redes de ami- } \\
\text { gos con formas } \\
\text { similares de } \\
\text { divertirse. }\end{array}$ & $\begin{array}{l}\text { Nuevas redes } \\
\text { de amigos, con } \\
\text { formas distintas } \\
\text { de divertirse. }\end{array}$ \\
\hline & \multirow{2}{*}{$\begin{array}{l}\text { Valoración } \\
\text { del circuito } \\
\text { de ocio con } \\
\text { amigos de } \\
\text { la escuela }\end{array}$} & \multirow{2}{*}{$\begin{array}{l}\text { Continuidad } \\
\text { del consumo } \\
\text { recreativo. }\end{array}$} & \multirow{2}{*}{$\begin{array}{l}\text { Aprendizaje } \\
\text { del consumo } \\
\text { recreativo. }\end{array}$} & $\begin{array}{l}\text { Continuidad de } \\
\text { sociabilidad al } \\
\text { margen del con- } \\
\text { sumo en espacios } \\
\text { comerciales. }\end{array}$ & $\begin{array}{l}\text { Aprendizaje de } \\
\text { sociabilidad al } \\
\text { margen del con- } \\
\text { sumo en espacios } \\
\text { comerciales. }\end{array}$ \\
\hline & & & & \multicolumn{2}{|c|}{$\begin{array}{l}\text { Descubrimiento del Mall como } \\
\text { espacio para la libertad y el ano- } \\
\text { nimato (función limitada). }\end{array}$} \\
\hline \multicolumn{2}{|c|}{$\begin{array}{l}\text { Posición en (des)ventaja de } \\
\text { su ocupación en el Mall }\end{array}$} & $\begin{array}{l}\text { Ventaja para } \\
\text { subvertir la vigi- } \\
\text { lancia del Mall. }\end{array}$ & $\begin{array}{l}\text { Ventaja para } \\
\text { subvertir la vigi- } \\
\text { lancia del Mall } \\
\text { con compañía } \\
\text { de nuevas redes } \\
\text { de amigos. }\end{array}$ & \multicolumn{2}{|c|}{$\begin{array}{l}\text { Desventaja para subver- } \\
\text { tir la vigilancia del Mall. }\end{array}$} \\
\hline
\end{tabular}

\section{territarias 44}

Fuente: elaboración propia (2020). 


\section{Malls en aumento: construyendo una Lima para ciudadanos consumidores}

Se ha revisado la hipótesis de que "los jóvenes usuarios del Jockey Plaza tienen mayor capacidad y seguridad para apropiarse del Mall que los de Megaplaza", considerando que nuestro grupo de estudio construyó parte importante de su vida cotidiana en el centro urbano donde el respectivo Mall se ubica, siendo de distintas jerarquías socioespaciales.

La evidencia empírica no apoya el argumento de que las situaciones de ventaja de los jóvenes en el Mall corresponden solamente a los distintos niveles y dispositivos de control que tiene cada centro comercial. La alta vigilancia ocurre tanto en Jockey plaza como en Megaplaza, pero son los grupos de jóvenes quienes se relacionan distinto con ella. Los jóvenes usuarios del Jockey Plaza se apropian del espacio como consumidores recreativos, siendo una práctica que los trabajadores no pueden limitar porque, aunque se desasocien del interés de comprar, operan dentro de las reglas del Mall, además de ser usos que dichos jóvenes defienden desde una conciencia práctica y discursiva. En cambio, los jóvenes usuarios de Megaplaza transitan entre la tensión y apropiación del espacio tras realizar allí actividades de encuentro y ocio, pero que pueden ser limitadas por los trabajadores en caso de que obstruyan los usos para el consumo, además de dudar de sus prácticas al estar al margen del consumo, creyendo que son vistos como objetos de sospecha.

La evidencia empírica tampoco apoya el argumento de que las situaciones de ventaja de los jóvenes en el Mall corresponden a capacidades y seguridades construidas desde disposiciones meramente individuales, en el marco de un proceso de diferenciación social. Por lo que nada tienen que ver con la clase social. Al contrario, los hallazgos demuestran que los usuarios del Jockey Plaza y Megaplaza cuentan con recursos culturales (redes sociales y circuitos de ocio) asociados al consumo recreativo, a la sociabilidad en espacios comerciales y la libertad del anonimato en el Mall respectivamente, poniendo a este primer grupo en ventaja. Estos recursos se adquieren o reproducen con su ingreso a la escuela, y la experiencia urbana que supone, ubicada en el entorno urbano del Mall.

Con base en lo anterior, se postula la existencia de una desigualdad intraclase en la experiencia de ocio entre jóvenes de la tradicional y la nueva clase media limeña que no se circunscribe a las lógicas del Mall sino a la escala ciudad, en tanto Lima siga destinando la producción de espacios privatizados y de consumo para las actividades de ocio y encuentro. Las tácticas que los jóvenes van adquiriendo para performar en el Mall están relacionadas a la socialización adquirida en el territorio que habitan, es decir, a las 
estructuras sociales que lo caracterizan. Es una condición permanente en las zonas de alta y renta media.

Los usuarios de Megaplaza demandan la existencia de espacios públicos seguros, tras valorar altamente el descubrimiento de la libertad del anonimato que el Mall suple gracias a las micro estrategias que ellos deben ensayar. En cambio, los usuarios del Jockey Plaza han aprendido o están aprendiendo a divertirse en espacios de consumo, demandando una mayor oferta recreativa de este tipo en la ciudad.

La producción de la ciudad de Lima privilegia al ciudadano consumidor que es de cierta posición de clase. Quienes tienen mayores capacidades y seguridades de clase para afirmar su derecho al uso del espacio, lo ejercen en su condición de clientes, mas no de ciudadanos. Por ese lado, concordamos con la literatura norteamericana, pero discrepamos en el hecho que la experiencia en Malls se ciñe a ser entre consumidores disciplinados, donde las desigualdades se reducen a la lógica de acceso/exclusión: la experiencia es mucho más compleja y ambigua como ya se ha revisado.

\section{Referencias}

Arellano Marketing. (2014, 29 de mayo). Estudios marcas 2014: categoría centros comerciales (Informe Final). Arellano Marketing. https://es.slideshare.

\section{tersitarias 44} net/ArellanoMarketing/marcas-2014
Arellano, R. (2010). Al medio hay sitio: el crecimiento social según los estilos de vida. Arrellano Marketing.

Ariovich, L., Parysow, J., \& Varela, A. (1996). Juegos en el shopping center. En M. Margulis (Ed.), La juventud es más que una palabra: ensayos sobre cultura y juventud (pp. 31-46). Editorial Biblos.

Asociación de centros comerciales y entretenimiento del Perú (ACCEP). (2015). Asociación de Centros comerciales del Perú: sector del desarrollo. http:// accep.org.pe/es/asociados/

Barbosa-Pereira, A. (2016). Os "rolezinhos" nos centros comerciais de São Paulo: juventude, medo e preconceito. Revista Latinoamericana de Ciencias Sociales, Niñez y Juventud, 14(1), 545557. http://revistaumanizales.cinde. org.co/index.php/Revista-Latinoamericana/article/view/2385

Bermúdez, E. T. (2003). Mall, consumo cultural y representaciones de identidad juvenil en Maracaibo. En D. Matos (Ed.), Politicas de identidades $y$ diferencias sociales en tiempos de globalización (pp. 173-192). FACES; UCV.

Borja, J. (2003). La ciudad conquistada. Alianza Editorial

Caldeira, T. (2014). Qual a novidade dos rolezinhos? Novos estudos CEBRAP, (98), 13-20. https://doi.org/10.1590/ S0101-33002014000100002

Crawford, M. (2004). El mundo en un centro comercial. En M. Sorkin (Ed.), 
Variaciones de un parque temático: la nueva ciudad norteamericana y el fin del espacio público (pp. 15-43). Gustavo Gili.

Chion, M. (2002). Dimensión metropolitana de la globalización: Lima a fines del siglo XX. Revisa EURE, 28(85), 7187. https://doi.org/10.4067/S025071612002008500005

Davis, M. (1990). City of Quartz: Excavating the Future in Los Angeles. Verso Books.

Da Silva, D., \& Da Silva, J. (2014). Rolezinhos: sociabilidades juvenis, discriminações e segregação urbana. Pensata, 3(2), 17-35

Frúgoli, H., \& Pintaudi, S. (1992). Shopping Centers: Espaco, Cultura e Modernidade nas Cidades Brasileiras. Editora de Universidade Estadual Paulista.

García Canclini, N. (1999). La globalización imaginada. Paidós.

Giglia, A. (2001). Sociabilidad y mega ciudades. Estudios Sociológicos, 19(57), 799-821. FLACSO. https://www.jstor. org/stable/40420690

Grupo Educación al Futuro (2020). EducaciónalFuturo.com. Consulta: 22 de Mayo del 2020. (https://educacionalfuturo.com/colegios/)

Huber, H., \& Lamas, L. (2017). Deconstruyendo el rombo: consideraciones sobre la nueva clase media en el Perú. Instituto de Estudios Peruanos.

Instituto Nacional de Estadística e Informática del Perú (2016). Planos estratificados de Lima Metropolitana a nivel de Manzana 2016. INEI.

Jiménez Domínguez, B., \& Becerra, O. (2009). Apropiación pública del espacio en centros comerciales de la zona metropolitana de Guadalajara. Medio Ambiente y Comportamiento Humano, 10(3), 253-285. https://www.sistemamid.com/panel/uploads/biblioteca/2016-02-11_07-02-51131966.pdf

Joseph, J. (2005). La ciudad, la crisis y las salidas. Universidad Nacional Mayor de San Marcos.

Judd, D. (1996). Enclosure, Community and Public Life. Research in Community Sociology, (6), 217- 236.

Ludeña, W. (2009). Urbanismo dixit. FLACsO. Matos Mar, J. (2004). Desborde popular y crisis del Estado. Veinte años después. Fondo Editorial del Congreso del Perú. Ministerio de Educación del Perú. (2020). Plataforma Ponteencarrera.pe. https:// www.ponteencarrera.pe/pec-portalweb/inicio/donde-estudiar

Observatorio ciudadano Lima Cómo Vamos. (2018). Encuesta Lima Cómo vamos 2017: VIII Informe de percepción sobre calidad de vida. Asociación Unacem; Grupo RPP; PUCP; Rimac Seguros. http://www.limacomovamos.org/ $\mathrm{cm} / \mathrm{wp}$-content/uploads/2018/03/ EncuestaLimaC\%C3\%B3moVamos_2017. pdf

Pereyra, O. (2006). Forma urbana y segregación residencial en Lima. Revista Debates en Sociologia, (31), 69-106. http://revistas.pucp.edu.pe/index. 
php/debatesensociologia/article/ view/2704

Pérez, M. (2010). Cuando los indeseados se congregan en el Mall: prácticas socioespaciales de adolescentes en un espacio semipúblico (Tesis de maestría). Pontificia Universidad Católica de Chile.

Pérez, M., Salcedo, R., \& Cáceres, G. (2012). Apropiación y control social en un centro comercial de Santiago: prácticas socioespaciales y significaciones adolescentes. Revista EURE, 38(113), 53-75. http://dx.doi.org/10.4067/ S0250-71612012000100003

Ritzer, G. (2003). Islands of the living dead: the social geography of McDonaldization. American Behavioral Scientist, 47(2), 119-136. https://doi. org/10.1177/0002764203256179

Salcedo, R. (2002). El espacio público en el debate actual: una reflexión crítica sobre el urbanismo post-moderno. Revista EURE, 28(84), 5-19.
http://dx.doi.org/10.4067/S025071612002008400001

Staeheli, L., \& Mitchel, D. (2006). USA's destiny? Regulating space and creating community in American shopping Malls. Urban Studies, 43(5-6), 977-992. https://doi. org/10.1080/00420980600676493

Stillerman, J., \& Salcedo, R. (2010). Es mucho más que comprar...Discursos y prácticas espaciales cotidianas en Malls de Santiago. Estudios Avanzados, (13), 79-103. https://tinyurl. com/ydebkfud

Vega Centeno, P. (2017). La dimensión urbana de las centralidades de Lima Norte: cambios y permanencias en la estructura metropolitana. Revisa EURE, 43(129), 5-25. http://dx.doi.org/10.4067/S025071612017000200001

Viana, N. (2014). O significado dos rolezinhos. Revista Posição, 1(1), 4-8. 